\title{
THE ROLE OF CHARACTERIZATION \& MODELING TECHNIQUES IN FOSTERING THE ERA OF COMPUTER-BASED CATALYST AND REACTOR DESIGN
}

\section{Authors}

Eseoghene Jeroro

Kurt Vanden Bussche 


\section{FEEDSTOCK AND PRODUCT CHARACTERIZATION}

The competitive environment of maximizing the output from Refinery and Petrochemical processes valorizes the feed components. Optimizing the process involves acquiring a detailed knowledge of the chemical composition of the feed stock, the product, and the impact of composition on product properties and quality. This is especially important when upgrading very heavy feeds such as vacuum residue as is the case in UOP's Uniflex® Process.

Advances in analytical characterization using Two- dimension Gas Chromatography (GC x GC, GC x GC-MS), Nuclear Magnetic Resonance (NMR), and High Resolution Mass Spectroscopy (HRMS) now allow for significant feed speciation [4-6]. Figure 1 illustrates how these techniques can be used as a function of the hydrocarbon boiling range, and how they can ultimately enable the concept of molecule management. By understanding the chemical complexity of the feed stock, the user can make educated choices around its conversion, separation, and blending such that the inherent chemistry of the molecules is utilized to its maximum potential in the Refining or Petrochemical complex.

A successful molecule management strategy involves feeding this data into fundamental kinetic models for analysis and application towards catalyst and process optimization. When sufficient computational efficiency is not available for modeling a large number of feed components, reconstruction techniques can be used to simplify the feed and product characterization data [7-9]. Some of these techniques are highlighted below:

- Maximization of Shannon Entropy (MSE) techniques: Starting with a predefined library of components, relative concentrations species are estimated by maximizing entropy, subject to constraints given by macroscopic properties [10,11].

- Neural net or linear regression approaches: Require detailed information e.g. a training set of compositions. Principal component analysis can then be applied to determine suitability of the technique with given bulk properties of a new feed stream vs. the training set $[8,12]$. 


\section{CATALYST CHARACTERIZATION}

Many Refining and Petrochemical catalytic processes are heterogeneous, involving the adsorption of reactants from a fluid phase onto a solid surface, the surface reaction of the adsorbed species, and the desorption of products into the fluid phase [15]. The active sites may be metal, acidic, or a combination of both, and are usually supported on an inert porous support. For many existing processes, significant innovations in catalytic performance can only achieved when the interplay between active phase and support, or between mass transfer and reaction are well understood. Usually, this cannot be gained by a single analytical method and requires a combination of spectroscopy, tomography, microscopy, and/or computational methods.

\section{Catalyst Morphology and Performance}

Spectroscopy, from IR through Raman and onto X-ray based techniques, elucidate the complex chemical relationships that exist in industrial catalysts between feed, active site, and support. The in-situ vs. operando terminology is often used to differentiate studies that simply probe of the morphology of the active site vs. studies where catalyst activity and reaction rates for model compounds on these sites are also determined [16]. Both approaches play a vital role in completely understanding the reactivity of a catalytic system.

Electron microscopic techniques are ideal for visualizing catalytic active sites at the atomic scale. In the 1970s, researches like Baker et al. [17] and Crewe et al. [18] were amongst the first to publish microscopic images of catalyst particles with Controlled Atmosphere Electron Microscopy (CAEM), and individual Thorium atoms with Scanning Transmission Electron Microscopy (STEM). More recently, Gai and Boyle [19] obtained High-Resolution TEM images under in-situ conditions at higher temperatures and pressures, and with flowing gases present. The remarkable innovations that have been made in sensitivity and image resolution mean that today, techniques such as Aberration-Corrected STEM can provide static or dynamic sub-angstrom $(<1.0 \mathrm{~A})$ images of catalytic surfaces under controlled fluid and temperature conditions [20]. Such microscopic methods can also be integrated with other spectroscopic techniques for extracting critical kinetic information for reactants on the surface [21]. For example, High-Resolution TEM analysis can be coupled with in-situ Ambient Pressure X-ray Photoelectric Spectroscopy (APXPS) to obtain the physical and chemical properties of catalyst nanoparticles at dynamic conditions [22].

With direct imaging of the active site, researchers can now observe the interplay between surface morphology, synthesis conditions, and catalyst performance. Figure 2 shows a STEM micrograph of a partially deactivated catalyst particle and highlights how this analysis can reveal the poisoning mechanism of destabilization agents such as coke. Carbon, shown in green, is heterogeneously deposited on the surface and appears to be present in significantly larger quantities in the vicinity of the metal phase, indicated in the figure with arrows. This observation was instrumental in identifying the specific modes of catalyst deactivation in this process, and assisted in the development of a more stable next generation catalyst.

One area that perhaps exemplifies the impact that progress in characterization techniques can have on discovery is the synthesis of new Zeolites. Zeolites are crystalline amino-silicates made up of $\mathrm{AlO}_{4}$ and $\mathrm{SiO}_{4}$ tetrahedral units linked through oxygen atoms. Since the discovery of the first zeolite structures in the 1890s, there has been an exponential rise in the synthesis of new zeolitic frameworks [23]. This rise could be partly attributed to the progress made in the resolution of techniques such as X-ray Diffraction (XRD), NMR, and Scanning Electron Microscopy (SEM). In addition to new material synthesis, work in this field also involves modifying the properties of wellknown zeolites to improve their performance in a particular reaction.

Take for instance the Mordenite zeolite (MOR). MOR is a dual-pore zeolite made up of 12-Ring channels interconnected in one direction by 8-Ring channels. Since most applications of MOR utilize only the 12-ring channels, it is considered to be a pseudo 1-Dimensional zeolite prone to diffusional limitations when its pores are blocked. The High Resolution SEM images in Figure 3 illustrate the reduction in MOR particle size observed after 
specific parameters in the synthesis were changed. These results helped finalize a recipe for a smaller crystallite MOR zeolite. The reduced length of the MOR particles in the direction parallel to the 12-ring channels minimized the reaction diffusion path, and was a critical factor in the design of a higher activity, more stable catalyst.

\section{Catalyst Morphology and Strength}

X-ray based micro-tomography (XMT) has recently become a core characterization capability [24-26]. XMT operates at a scale similar to SEM for visualizing catalyst structure, impacts of synthesis conditions etc. However, it transcends the limitations of SEM in accessing catalyst structure in three dimensions, as well as in allowing in-situ experimentation on aspects such as attrition resistance. Figure $\mathbf{4}$ shows a test cell used to monitor the crushing of a bed of catalyst by means of XMT. The cell, containing a few thousand catalyst pellets, is rotated stepwise in an Xray beam while its projection is recorded by a detector array as a time series. These images are then processed to reconstitute a 3-dimensional image of the bed, as shown in Figure 4b. This image can be further analyzed to calculate touch points between the catalyst trilobes, shown in red, in Figure 4c. As the pressure is increased on the pills in the cell, the catalyst starts to break up, resulting in smaller particles and an increase in the number of contact points. All of this information can be fed into computational fluid dynamics tools, enabling the correlation of catalyst strength to pressure drop in a catalyst bed.

\section{Computational Chemistry for Catalyst Design}

Computation chemistry is rapidly becoming an invaluable tool for benchmarking the chemical intuition of the researcher, and expanding the definition of what a catalyst can look like. Growth in this field is fueled by advances in computer processing speeds and novel methods for approximating electron density calculations [27]. Researchers now have the ability to conduct reaction path analysis, transition state predictions, energy minimization of structures in the presence of solvents like water or hydrocarbons and two-phase partition coefficients, in an unbiased ab initio fashion [28-30].

The most frequently used methods for connecting electronic structure to catalyst performance are Standard ab initio wave function and Density Functional Theory (DFT) [27]. DFT has perhaps had the largest impact on heterogeneous catalysis since improvements in calculation kinetics make this approach a viable candidate for computer-based catalyst design [31]. As early as 2001, Yajima et al. used computational chemistry to predict new catalysts for $\mathrm{DeNO}_{\mathrm{x}}$ reactions that would show a higher tolerance to $\mathrm{SO}_{\mathrm{x}}$ in the feed [32]. More recent DFT studies have identified promising catalytic surfaces for hydrogen evolution [33] and carbon dioxide reduction [34]. DFT has also proved to be a very valuable tool in the elucidation of complex reaction mechanisms in the areas of Hydroprocessing [35] and Ammonia Synthesis [36].

The use of DFT, and computational chemistry in general, as part of a catalytic design strategy is now common-place but its role is still mostly limited to guiding the intuition of material scientists and confirming or disproving, at least theoretically, the validity of certain reaction paths and the energetics around certain proposed transition states. The focus of such studies would have to change in order to make computation chemistry a truly predictive vehicle for catalyst design. It is rare to find theoretical studies that instead of activity, assess catalyst stability, performance in the presence of competing reactants, and selectivity to un-desired side products. Norskov et al. [31] have also proposed the use of DFT for intelligent reactor design where the catalyst structure is optimized as a function of the different reaction conditions that can exist within a single reactor or process.

Finally, the web application 'CatApp' developed by Stanford deserves to be mentioned here. This site gives the public unrestricted access to a wide library of DFT-calculated reaction and activation energies and in the future, may play a role in expanding the outreach of computational chemistry [37].

\section{PERFORMANCE EVALUATION}

A standard catalyst or process design workflow ends with the evaluation of promising concepts identified in proof of principle screening, by characterization or computation methods. The evaluation process should ideally generate 
fundamental kinetic information that can be used to identify new concepts for further pursuit, or extrapolated to predict performance under commercially relevant process conditions [38].

\section{High Throughput Catalyst Screening}

The large throughput and rapid turnaround provided by High-throughput Experimentation (HTE) can promote significant innovation within a catalyst development program. With the ability to screen 'thousands' of ideas, researchers are more likely to break away from the "moth around the flame" analogy and explore novel catalytic ideas that are more likely to lead to significant breakthroughs [39].

HTE has customarily been used as a catalyst screening tool so its online analytical capability is geared towards more qualitative than quantitative analysis, and detailed analysis is sacrificed at the expense of speed. In a typical application, successful concepts in the initial screening are then re-evaluated on a larger scale to extract useful kinetic information. Unfortunately, this practice results in a loss of mechanistic information on candidate materials that were found lacking in the initial test.

Maximizing the use of HTE as a kinetic data extraction tool would require improving the speeds of analytical tools such as scanning GC-MS, without compromising accuracy. Alternative techniques like spatially-resolved Fourier Transform Infrared (FTIR) imaging have also shown promising results for obtaining kinetic information in a truly parallel manner [40], but currently fall woefully short when complex feed stocks need to be processed.

\section{Characterization of solids and liquids in flow environment}

Evaluating the performance of two or three phase flow systems, which commonly occur in refining and petrochemical processing often relies on Computational Fluid Dynamics calculations [41,42], or the use of NMR or Magnetic Resonance Imaging (MRI) to model flow thermodynamics within the reactor [43]. Validating these calculations against physical measurements is critical for ensuring the accuracy of the models.

UOP has developed a cold-flow modeling set up for validating CFD predictions, in which flow and pressure can be visualized and measured under representative conditions. In some cases, techniques like Computer Aided Radioactive Particle Tracking (CARPT) can also be employed to study the flow of solids or the relative slip of solids and liquids, for instance where transparent materials cannot be used. Figure 5 shows a cold flow modeling setup, as operated at UOP. It features a $2.4 \mathrm{~m}$ diameter vessel and a series of sample collectors, showing in the lower $1 / 3$ of the picture. The rig is used to evaluate gas and liquid distribution in novel tray designs; additionally, the tool can be applied to study ease of installation in the field and for evaluating sensitivity of flow distribution to off-spec installation.

The test rig in Figure 5 was used to confirm the CFD results for UOP's next generation of Hydroprocessing reactor internals. Figure 6 shows typical pressure profiles for an initial vs. the final design, clearly illustrating the superior flow distribution as well as the power of the combined use of CFD with cold flow modeling.

\section{SUMMARY}

This review briefly summarizes how the Chemical Reaction Engineering (CRE) field is contributing to better and faster catalyst design, and identifies some areas for growth in the next decade. While we are still falling woefully short of the ultimate goal of 'computer designed catalysts', innovations in feed and catalyst characterization tools can enable the concept of molecule management, and when combined with computational chemistry, are crucial for understanding the complex phenomena at the catalyst surface required for developing breakthrough catalysts. Finally, CFD and cold-flow experimentation can be synergistically combined to largely eliminate the scale up risk associated with developing process equipment.

\section{ACKNOWLEDGEMENT}


The authors acknowledge stimulating discussions with their many colleagues in the R\&D and Technical Services community at UOP, as well as with our customers, who continuously provide valuable feedback to help us further improve our technologies.

Use of the Advanced Photon Source, an Office of Science User Facility operated for the U.S. Department of Energy (DOE) Office of Science by Argonne National Laboratory, was supported by the U.S. DOE under Contract No. DEAC02-06CH11357. MRCAT operations are supported by the Department of Energy and the MRCAT member institutions. 


\section{References}

1. 'BP Energy Outlook: 2016 Edition,' BP Global, 2016 (https://www.bp.com/content/dam/bp/pdf/energyeconomics/energy-outlook-2016/bp-energy-outlook-2016.pdf).

2. 'The Outlook for Energy: A View to 2040,' ExxonMobil Corporation, 2016 (http://cdn.exxonmobil.com/ /media/global/files/outlook-for-energy/2016/2016-outlook-for-energy.pdf).

3. 'Annual Energy Outlook 2015, with Projections to 2040,' DOE/EIA Publication no. 0383, Energy Information Administration, U.S. Dept. of Energy, April 2015 (http://www.eia.gov/forecasts/aeo/ pdf/0383(2015).pdf).

4. Dijkmans T, Djokic MR, Van Geem KM, Marin GB: Comprehensive compositional analysis of sulfur and nitrogen containing compounds in shale oil using GCxGC - FID/SCD/NCD/TOF-MS. Fuel 2015, 140, 398-406.

5. Sugumaran V, Biswas H, Yadav A, Christopher J, Kagdiyal V, Patel MB, and Basu B: Molecular-Level Characterization of Refinery Streams by High-Resolution Mass Spectrometry: Energy Fuels 2015, 29, 2940-2950.

6. Hauser A, AlHumaidan F, Al-Rabiah H, Halabi MA: Study on thermal cracking of Kuwaiti heavy oil (vacuum residue) and its SARA fractions by NMR spectroscopy. Energy \& Fuels 2014, 28:7, 43214332.

7. Klein MT, Hou G, Bertolacini RJ, Broadbelt LJ, Kumar A: Molecular Modeling in Heavy Hydrocarbon Conversions, CRC Press, 2006.

8. Pyl S, Van Geem K, Reyniers M-F, Marin G: Molecular reconstruction of complex hydrocarbon mixtures: an application of principal component analysis. AICHE $J$ 2010, 56:12, 3174-3188.

9. Froment GF: Single Event Kinetic Modeling of Complex Catalytic Processes, Catal Rev 2005, 47:1, 83124.

10. Hudebine D, Verstraete JJ: Reconstruction of petroleum feedstocks by entropy maximization. Application to FCC gasolines. Oil Gas Sci Technol 2011, 66, 437-460.

11. Alvarez-Majmutov A, Chen J, Gieleciak R, Hager D, Heshka N, Salmon S: Deriving the Molecular Composition of Middle Distillates by Integrating Statistical Modeling with Advanced Hydrocarbon Characterization. Energy Fuels 2015, 29, 7931-7940.

12. Pereira de Oliveiraa L, Verstraetea JJ, Kolbb M: Simulating vacuum residue hydroconversion by means of Monte-Carlo techniques. Catal Today 2014, 220, 208-220.

13. Quam RJ, Jaffe SB: Structure-Oriented Lumping: Describing the Chemistry of Complex Hydrocarbon Mixtures. Ind. Eng Chem Res 1992, 31:11, 2483-2497.

14. Quann RJ, Jaffe SB: Building useful models of complex reaction systems in petroleum refining. Chem Eng Sci 1996, 51, 1615-1635.

15. Davis ME, Robert JD: Fundamentals of chemical reaction engineering. Courier Corporation, 2012.

16. Tao F, Crozier PA: Atomic-Scale Observations of Catalyst Structures under Reaction Conditions and during Catalysis. Chem Rev 2016, 116, 3487-3539.

17. Baker RTK: In Situ Electron Microscopy Studies of Catalyst Particle Behavior. Catal Rev 1979, 19:2, 161-209.

18. Crewe AV, Wall J, Langmore JP: Visibility of single atoms. Science 1970 168:3937, 1138-1140.

19. Boyes ED, Gai PL: Environmental high resolution electron microscopy and applications to chemical science. Ultramicroscopy 1997, 67, 219-232.

20. Pennycook TJ, Jones L, Pettersson H, Nicolosi V, Nellist PD: Probing Atomic Scale Dynamics with STEM. Microscopy and Microanalysis 2014, 20, 104-105. (*The authors show how the rapid scanning capability of STEM can be applied towards obtaining dynamic images of a catalytic surface).

21. Helveg S: An industrial perspective of the impact of Haldor Topsøe on (in situ) electron microscopy in catalysis. J Catal 2015, 328, 102-110.

22. Alayoglu S, Somorjai G: Ambient Pressure X-ray Photoelectron Spectroscopy for Probing Monometallic, Bimetallic and Oxide-Metal Catalysts under Reactive Atmospheres and Catalytic Reaction Conditions. Top Catal 2016, 59:5, 420-438 (*This article gives an overview of how Synchrotron-based insitu Ambient Pressure X-ray Photoelectron Spectroscopy (APXPS) can be used to analyze catalytic surfaces on the molecular- and nano-scale under dynamic conditions).

23. Baerlocher C, McCusker LB, Olson DH: Atlas of zeolite framework types. Elsevier, 2007.

24. Meirer F, Kalirai S, Morris D, Soparawalla S, Liu Y, Mesu G, Andrews JC, Weckhuysen BM: Life and death of a single catalytic cracking particle. Sci Adv 2015, 1, doi: 10.1126/sciadv.1400199. 
25. DaSilva JC, Mader K, Holler M, Haberthür, D, Diaz A., Guizar-Sicairos M, Cheng WC, Shu Y, Raabe J, Menzel A, Van Bokhoven, JA: Assessment of the 3 D Pore Structure and Individual Components of Preshaped Catalyst Bodies by X-Ray Imaging. ChemCatChem 2015, 7:3, 413-416.

26. Wei Y, Parmentier TE, and De Jong KP, Zečević J: Tailoring and visualizing the pore architecture of hierarchical zeolites. Chem Soc Rev 2015, 44, 7234-7261.

27. Neurock M: Theory and Simulation in Catalysis. International Assessment of Research and Development in Catalysis by Nanostructured Materials 2011, 91-150.

28. Jensen, F: Introduction to computational chemistry. John Wiley \& Sons, 2013.

29. Helgaker T, Jorgensen P, Olsen J: Molecular electronic-structure theory. John Wiley \& Sons, 2014.

30. Koch W, Holthausen MC: A chemist's guide to density functional theory. John Wiley \& Sons, 2015.

31. Norskov JK, Bligaard T, Rossmeisl, J, Christensen CH: Towards the computational design of solid catalysts. Nature Chem 2009, 1, 37-46.

32. Yajima K, Ueda Y, Tsuruya H, Kanougi T, Oumi Y, Ammal SSC, Takami S, Kubo M, Miyamoto A: Computer-Aided Design of Novel Heterogeneous Combinatorial Computational Chemistry Approach. Studies in Surf Sci Catal 2000, 130, 401-406.

33. Li H, Tsai C, Koh AL, Cai L, Contryman AW, Fragapane AH, Zhao J, Han HS, Manoharan HC, AbildPedersen F, Nørskov JK: Activating and optimizing $\mathbf{M o S}_{2}$ basal planes for hydrogen evolution through the formation of strained sulphur vacancies. Nature Mater 2016, 15:1, 48-53. (* DFT was used to show how the inert basal plane of $\mathrm{MoS}_{2}$ can be activated for the hydrogen evolution reaction by introducing sulphur vacancies and strain. Theoretical results are validated with experimentation).

34. Chan K, Tsai C, Hansen HA, and Nørskov JK: Molybdenum Sulfides and Selenides as Possible Electrocatalysts for $\mathbf{C O}_{2}$ Reduction. ChemCatChem 2014, 6, 1899-1905.

35. Moses PG, Grabow LC, Fernandez EM, Hinnemann B, Topsøe H, Knudsen KG, Nørskov JK: Trends in hydrodesulfurization catalysis based on realistic surface models. Catal Lett 2014, 144:8, 1425-1432.

36. Kitano M, Kanbara S, Inoue Y, Kuganathan N, Sushko PV, Yokoyama T, Hara M, Hosono H: Electride support boosts nitrogen dissociation over ruthenium catalyst and shifts the bottleneck in ammonia synthesis. Nature Comm 2015, 30, 6.

37. Hummelshøj JS, Abild-Pedersen F, Studt F, Bligaard T., Nørskov, JK: CatApp: A Web Application for Surface Chemistry and Heterogeneous Catalysis. Angew Chem Int Ed 2012, 51, $272-274$.

38. Hattrick-Simpers J, Wen C, Lauterbach J. The materials super highway: integrating high-throughput experimentation into mapping the catalysis materials genome. Catal Lett 2015, 145:1, 290-298. (* An interesting article that highlights how high-throughput experimentation (HTEs) can be used to create an "HTE materials superhighway'. In this concept, HTE is the link for bringing new material concepts from advanced characterization and computational methods to fruition).

39. Farrusseng D: High-throughput heterogeneous catalysis. Surf Sci Rep 2008, 63, 487-513.

40. Lauterbach J. Spectroscopic Imaging in the Mid-Infrared Applied to High-Throughput Studies of Supported Catalyst Libraries. High-Throughput Analysis: A Tool for Combinatorial Materials Science 2012, 77.

41. Alvarez-Castro HC, Matos EM, Mori M, Martignoni W, Ocone R: The influence of the fluidization velocities on products yield and catalyst residence time in industrial risers. Advanced Powder Technology 2015, 26:3, 836-847.

42. Zhuang YQ, Chen XM, Luo ZH, Xiao J: CFD-DEM modeling of gas-solid flow and catalytic MTO reaction in a fluidized bed reactor. Computers \& Chemical Engineering 2014, 60, 1-6.

43. Sankey MH, Holland DJ, Sederman AJ, Gladden LF: Magnetic resonance velocity imaging of liquid and gas two-phase flow in packed beds. J. Magn. Reson 2009, 196:2 142-148 


\section{List of Figures}

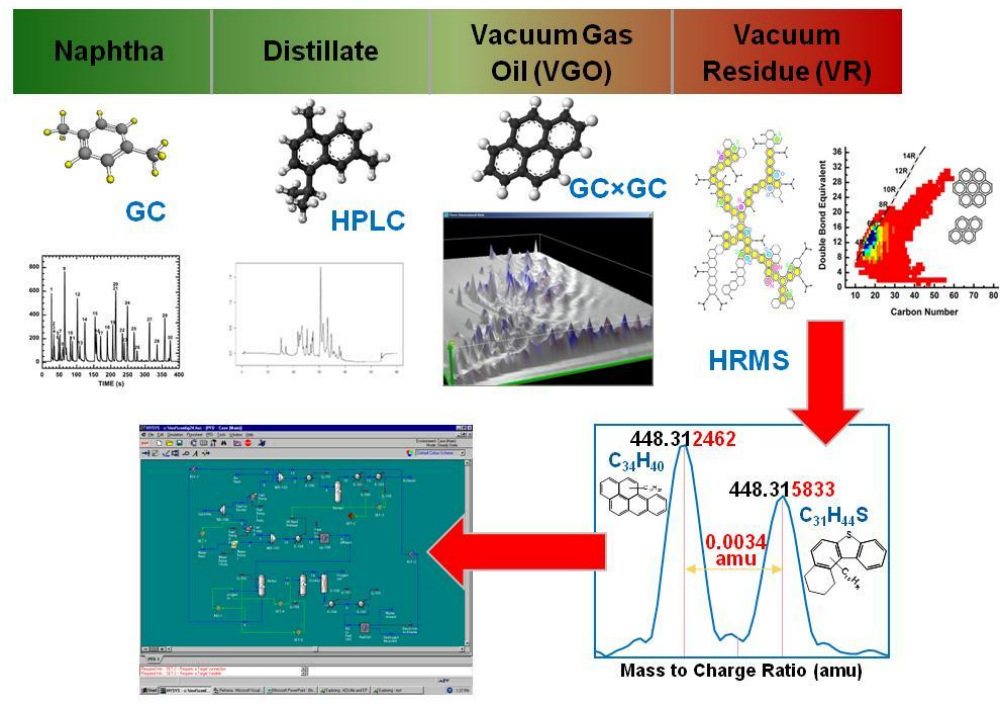

Figure 1: Overview of analytical techniques applied to petroleum boiling cuts and their incorporation into a molecule management strategy

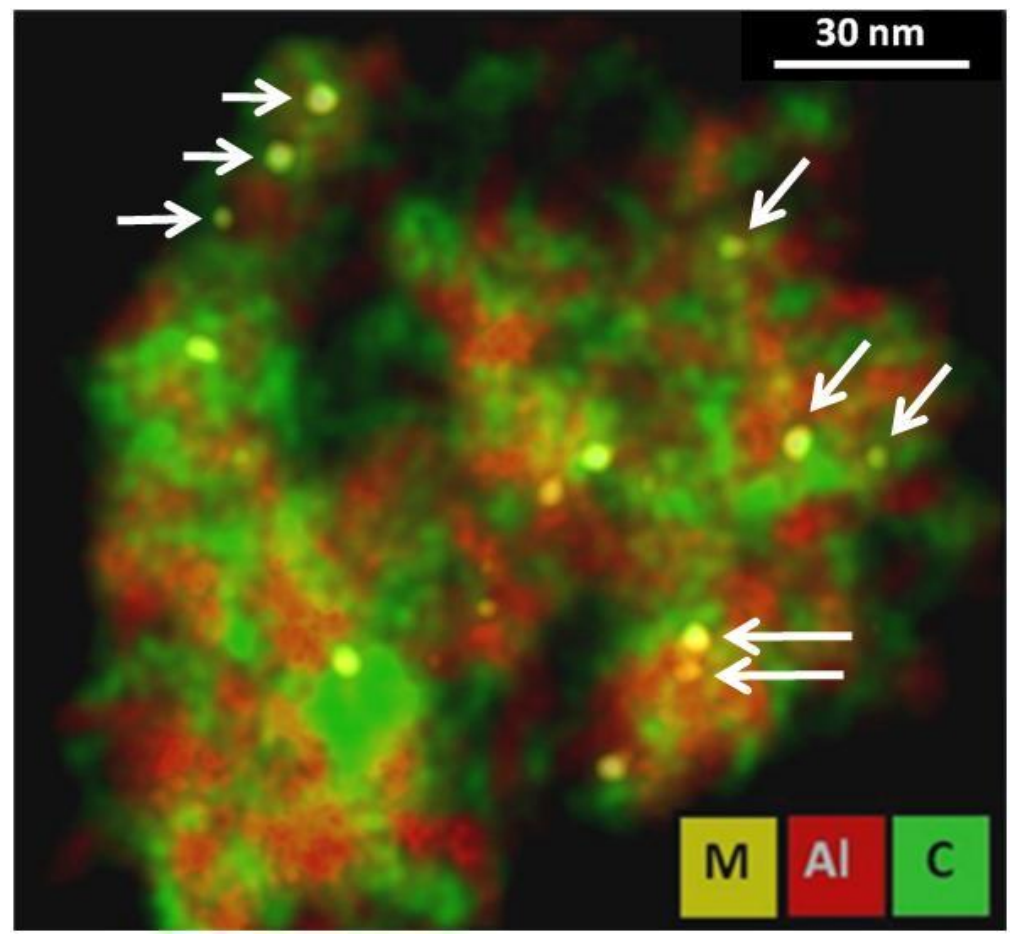

Figure 2: AC STEM micrograph of a deactivated catalyst showing heterogeneity in the location of the coke 


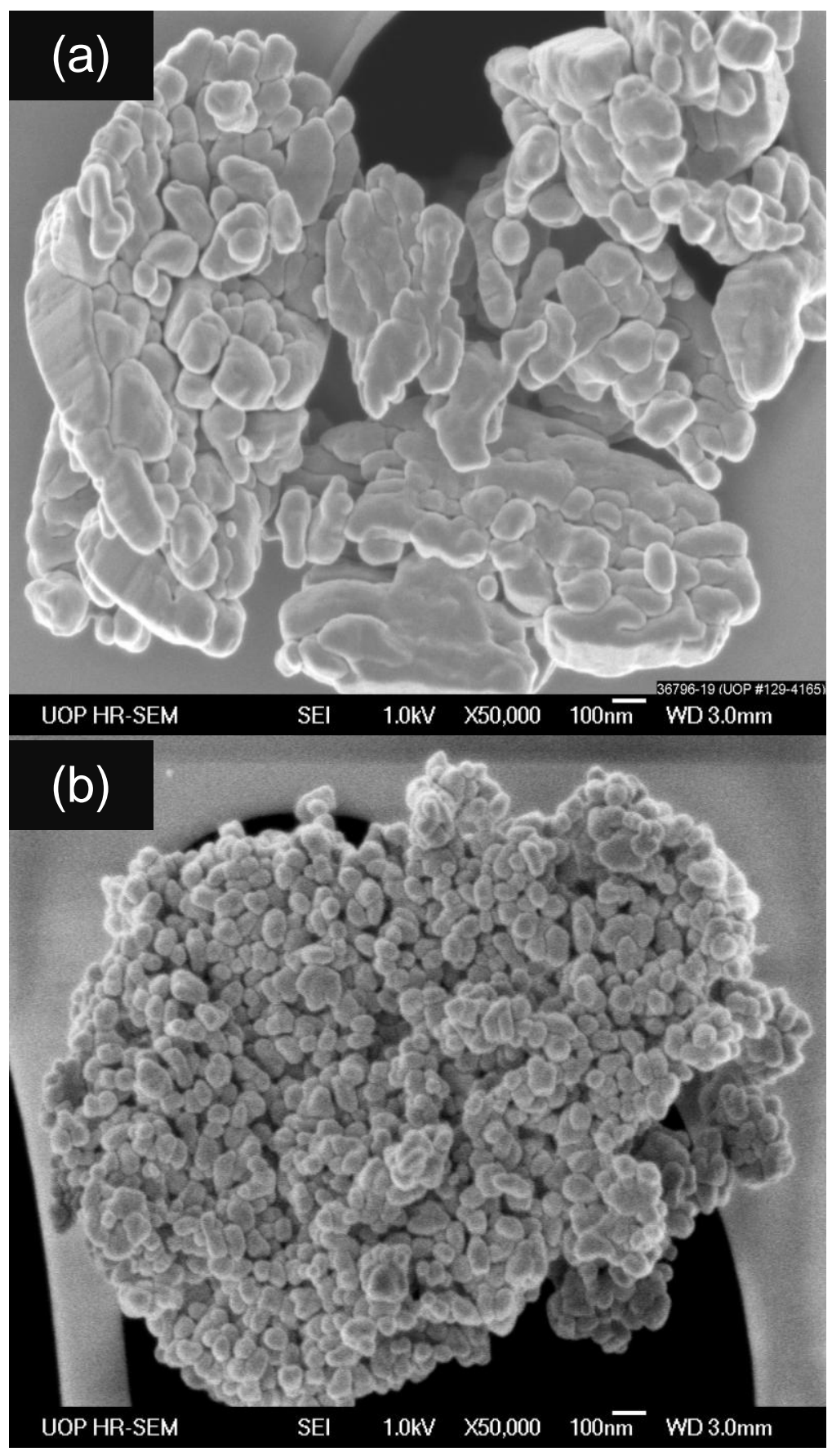

Figure 3: HR SEM images of Mordenite zeolite showing (a) reference crystallite size and (b) reduced crystallite size achieved by optimizing the synthesis conditions 

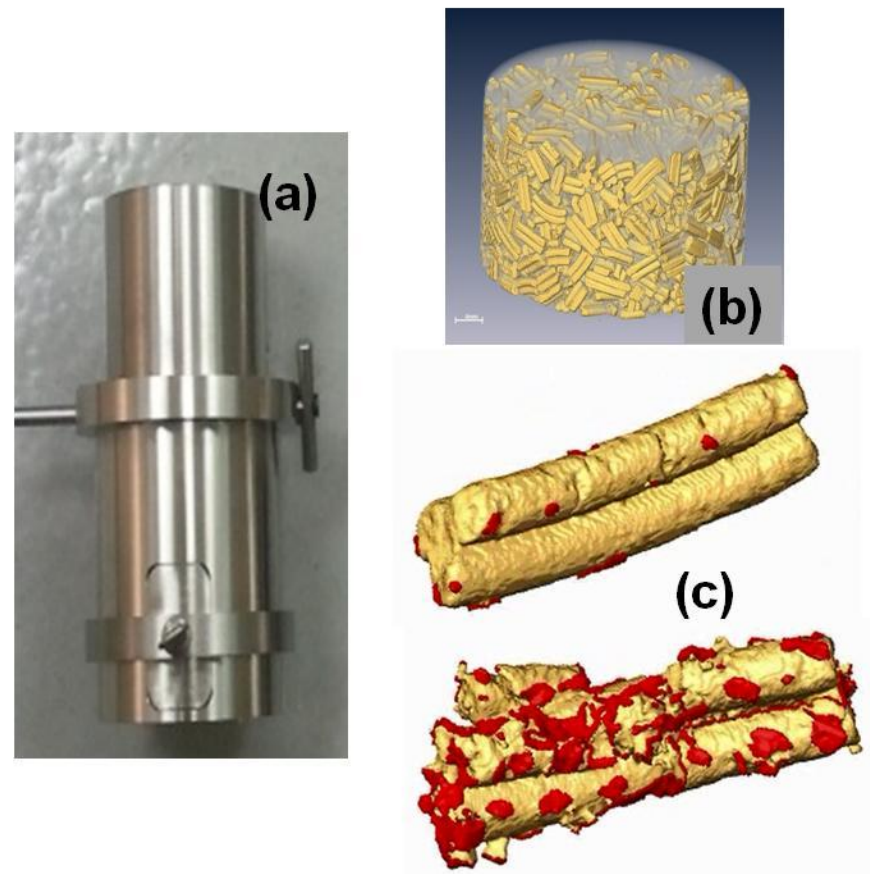

Figure 4: Tomography of a catalyst bed to assess pellet failure modes. (a) test cell, designed to contained a few thousand pills. (b) typical tomogram of a catalyst bed (c) evolution of catalyst breakage and contact points (shown in red) as pressure is increased on the bed. 


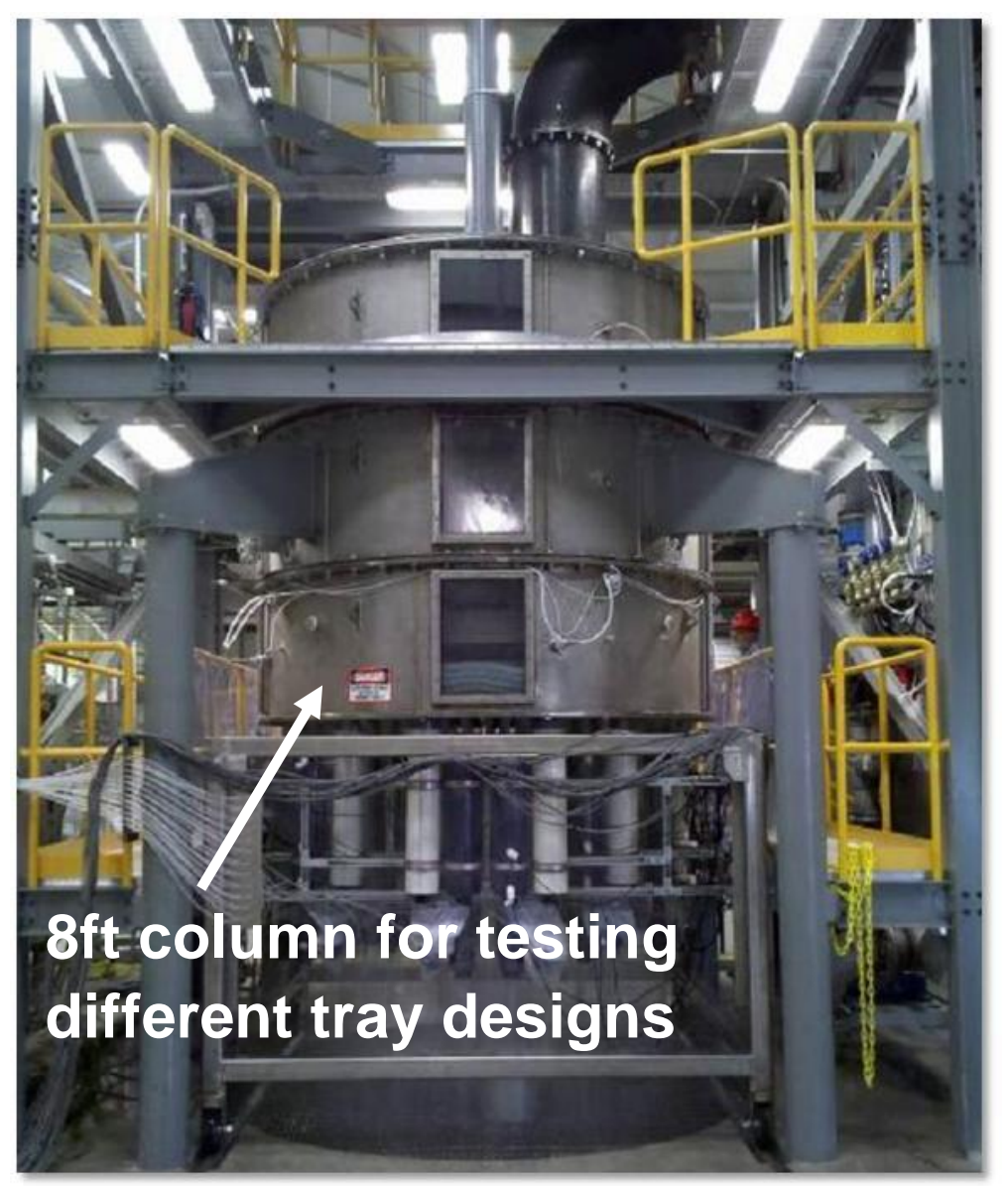

Figure 1: Cold flow modeling test rig to validate design of Gas/Liquid distributor tray and calibrate Computation Fluid Dynamics results 


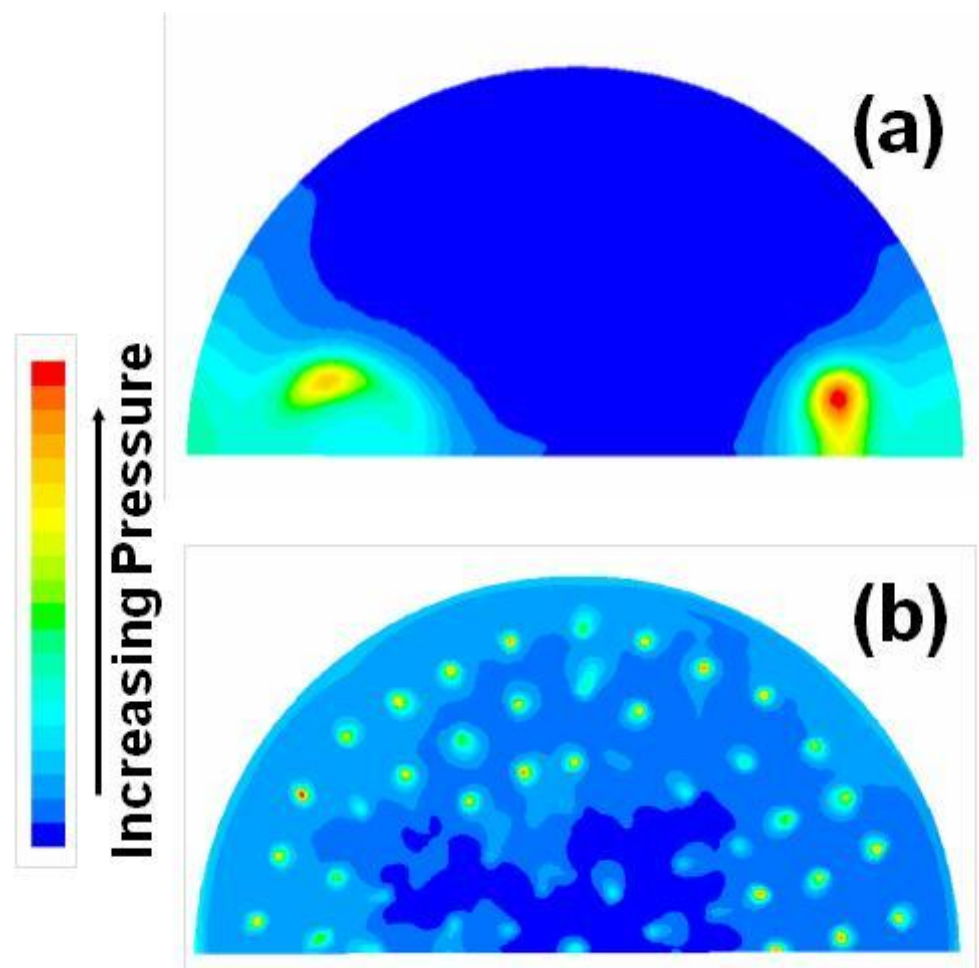

Figure 2: Pressure profiles predicted through computational fluid dynamics tools for the initial (a) vs. the final (b) design for a novel distribution tray 